Revista de la red interuniversitaria de estudios sobre las literaturas rioplatenses contemporáneas en Francia

19 | 2018

La rebelión de los hijos: el judaísmo en la literatura latinoamericana contemporánea entre tradición y asimilación

\title{
El silencio como llave: Nora Strejilevich y Mauricio Rosencof, lectores de PinieWald - Avatares rioplatenses de una tradición judía
}

Perla Sneh

\section{OpenEdition}

Edición electrónica

URL: http://journals.openedition.org/lirico/6274

DOI: $10.4000 /$ lirico.6274

ISSN: 2262-8339

Editor

Réseau interuniversitaire d'étude des littératures contemporaines du Río de la Plata

Referencia electrónica

Perla Sneh, «El silencio como llave: Nora Strejilevich y Mauricio Rosencof, lectores de PinieWald Avatares rioplatenses de una tradición judía », Cuadernos LIRICO [En línea], 19 | 2018, Puesto en línea el 20 enero 2019, consultado el 20 abril 2019. URL : http://journals.openedition.org/lirico/6274 ; DOI 10.4000/lirico.6274

Este documento fue generado automáticamente el 20 abril 2019.

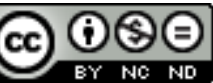

Cuadernos LIRICO está distribuido bajo una Licencia Creative Commons Atribución-NoComercialSinDerivar 4.0 Internacional. 


\section{El silencio como llave: Nora Strejilevich y Mauricio Rosencof, lectores de PinieWald -Avatares rioplatenses de una tradición judía}

Perla Sneh

\section{ESCRITURA EN LA ESCRITURA}

Pinie Wald, Mauricio Rosencof, Nora Strejilevich. ¿Qué reúne a estos nombres? En principio, nada: ni la cronología, ni la academia, ni la crítica. Hay, quizás, un tenue denominador común: los aires libertarios, las reivindicaciones sociales, los fragores ideológicos que, de un modo u otro, invisten sus textos de militancia y testimonio. Sin embargo, quien conozca algo de las causas latinoamericanas de los últimos tiempos sabrá que tampoco en ese punto se encuentran más que en algunos trazos ${ }^{1}$. Comparten, sí, un ámbito: el Río de la Plata, ese río que, en años oscuros y no tan lejanos, se volvió cementerio marino, haciendo de las ciudades que une y separa -Buenos Aires y Montevideo- tierra de sobrevivientes.

Ese espacio inquietante podría ser ocasión de un estudio detenido de la obra completa de los tres autores -valiosa, cautivante, variada-, pero no es lo que pretendemos en esta lectura, preliminar y tentativa. Acá solo queremos centrarnos en un texto específico de cada autor, particular por su circunstancia, aunque atravesado cada uno de ellos por un mismo y singular hilo que los acerca en un aspecto quizás inesperado: cierta relación a lo judío.

Seguramente, no es el único abordaje posible de estos textos -breves e intensos-, pero es el que aquí nos interesa debido a su entramado con algo que quizás los propios autores no 
necesariamente reivindicarían como elemento central de su escritura. Sin embargo, es ahí donde esta lectura los encuentra.

Ahí: en ese lugar nada se presta a la generalización, todo es singularidad y diferencia. Lo judío en $W^{2} a^{2}$ es una experiencia tan espontánea y evidente que el autor no precisa explicitarla más allá de la palabra pogróm (al menos no en el texto aquí considerado), mientras que para Strejilevich ${ }^{3}$ y Rosencof ${ }^{4}$ ) -de distintas maneras- lo judío parece estar presente como ámbito más complejo, aludido en formas más oblicuas, vacilantes.

Esta experiencia de lo judío no deja de anclar en la lengua, una lengua que -más allá del idioma de cada uno (ídish para Wald, castellano rioplatense para Strejilevich ${ }^{5}$ Rosencof ) porta los efectos de una otra lengua, esa lengua indescifrable que -apelando a Stéphane Moses- Edgardo Dobry llama "escritura ilegible" o "Ley presente e inaccesible a la vez" (2017). Se trata de una lengua "extremadamente saturada de significado, pero indescifrable por olvidada o nunca suficientemente aprendida" (Dobry). Una lengua que se va componiendo al calor del choque del mundo judío tradicional con la modernidad, así como de los combates culturales que esto desata. Veremos que esa lengua indescifrable ¿podemos decir: escritura cifrada en la escritura?- también surge aquí -en estos textos, en esta lectura-, por momentos, bajo la forma del silencio.

Asimismo, veremos que, aún con todas sus diferencias, los tres autores coinciden en retomar una de las tradiciones judías más vitales de la actualidad: la de la respuesta judía a la catástrofe $e^{6}$. Podríamos decir que Strejilevich y Rosencof son inadvertidos lectores -en el sentido borgeano de la palabra- del Wald que escribe Koshmar, un texto que quizás no han frecuentado, pero que seguramente han percibido en los silencios que tanto conocen, esos silencios que pueden haber cuestionado, disfrutado, despreciado, alentado, pero nunca dudado de la realidad de los personajes que lo pueblan.

Los textos aquí en juego son Koshmar (Pesadilla) ${ }^{7}$, de Pinie Wald, Una sola muerte numerosa ${ }^{8}$, de Nora Strejilevich y Las cartas que no llegaron', de Mauricio Rosencof, textos que proponemos abordar con menos ánimo crítico que entusiasmo lector.

\section{LA PALABRA ALERTA}

"Este es el Palacio de Justicia", escribí con ese lápiz sobre la pared negra.

Pinie Wald

Suele decirse que la literatura judía argentina arranca con Alberto Gerchunoff; algunos dicen, en cambio, con Samuel Eichelbaum. No es este el lugar para resolver ese debate, pero no debiera desconocerse que estos autores -sin duda relevantes-, fueron precedidos por un amplio número de escritores que volcaron sus experiencias argentinas en la lengua que trajeron consigo: el ídish. Es en esta lengua que fueron escritas estas palabras:

En mi cabeza resonaban estas frases: "dictador" ... "presidente" ... "bomba" ... yo

había bebido sangre... como señal del juramento que había prestado para hacerme

cargo del liderazgo del levantamiento... de pronto sentí punzada, como de agujas,

en la parte hinchada de mi rostro: Mi boca ensangrentada había explotado: ¡Estallé

en risas! (1987, p. 349)

Son palabras que hablan de un pogromo ocurrido en Buenos Aires ${ }^{10}$, durante la así llamada "Semana Trágica". Fueron días de salvajismo y atropello que arrancaron en la Sociedad Hierros y Aceros Limitada de Vasena e Hijos, cuyos obreros reclamaban reducir la jornada de once a ocho horas, y el descanso dominical. "Era poco y se lo consideró excesivo" dice, 
con justicia, Christian Ferrer (2006). El 7 de enero de 1919 hubo cuatro muertos y treinta heridos; dos días después, el cortejo fúnebre fue atacado. A partir de ahí, todo fue "batida, cacería y tiros de gracia” (Ferrer, 2006, 93) ${ }^{11}$. Al grito de “¡Muerte a los judíos!”, la turba cayó sobre el barrio de Once a ejercer "la caza del ruso"12. Buenos Aires se volvió un campo de degüello; Ferrer (op. cit, p.93) se asombra -y con razón- de que una matanza de tal magnitud se disolviera misteriosamente en la memoria de los porteños, como un mal sueño. Pero ese mal sueño será, precisamente, materia y título del escrito de Wald al cumplirse diez años de los sucesos: Koshmar (Pesadilla) ${ }^{13}$, publicado en 1929.

Existen varios trabajos sobre el texto de Wald, con diversos énfasis: sociológico, histórico, ideológico, rara vez literario, salvo por lo que hace a la definición del género en que debiera inscribirse ${ }^{14}$. Pronto se cumplirán cien años de los sucesos que Wald insistió en no dejar caer en el olvido y aún se discute si Koshmar es novela o crónica, o ambas a la vez ${ }^{15}$. Hay quien ubica a Wald como precursor de Walsh y pionero del género testimonial ${ }^{16}$. Hay quien considera el texto como registro de real fiction o non fiction ${ }^{17}$. No es esta la discusión a la que aquí apuntamos. Solo queremos subrayar un rasgo que, por lo general, los estudios dejan de lado, y es que Wald es, ante todo, un escritor ídish, es decir, un autor inmerso en la cultura ídish del momento.

Y esta lengua era, por entonces, la escena privilegiada de enardecidos combates culturales e ideológicos. Son los tiempos de prevalencia de los grandes clásicos literarios y -al menos en Argentina, pero no solo- de literatura aluvional. Todos escriben: sas Verbuet carpinteros (como Wald), vendedores, talleristas y hasta escritores, pero incluso en ese caso, los textos llegan al lector principalmente a través de los periódicos (Botoshansky); de allí el tono que caracterizaba la escritura de estos creadores literarios, tono que combina el folletín y la crónica con el periodismo y la novela ${ }^{18}$. Como tantos autores, Wald se nutre de la herencia de un judaísmo embebido de humanismo secular, herencia alimentada tanto por Dante, Tolstoi y Bloch como por Job, Yehuda Halevi y Bialik ${ }^{19}$. Como tantos autores de su época, Wald mantiene, aún si a los gritos, un diálogo intenso con el propio pasado cultural, con la propia tradición.

La generación de Pinie Wald tuvo el empuje requerido para desafiar al desierto que la modernidad abría para el judío que no era observante pero tampoco quería dejar de lado su judaísmo. Pero Wald no precisa, como dijimos, andar explicando nada. Si le preguntan a qué nación pertenece, responde: A la judía. Si le preguntan por su religión, responde: socialismo (1987, p. 348-9). Le produce risa que lo tilden de "maximalista", pero no se asombra de que lo acusen de beber sangre como señal de juramento ritual ${ }^{20}$. Es que él conoce todas las gamas de la persecución, conoce los libelos de sangre, conoce las palabras dichas con odio. La metáfora que le surge, espontánea, para sus torturadores es la de "el Santo Oficio". No es casualidad que, en esos días, Buenos Aires le evoca a la Lodsz de 1905 (a la que arriba después del pogróm de Kischinev ${ }^{21}$ ) donde caminó "entre muerte y fuego" el día de las barricadas (1987, p. 333). La retórica de Wald parece invocar una especie de reiterado dejà-vu, alimentado por una historia que no deja de reconocer. Porque si bien Wald no precisa definirse como judío, no desconoce lo que esto implica. Es quizás por eso, por ese no desconocimiento, que Wald no deja de reconocer el valor de la escritura como arma, un arma que permite, en medio de la catástrofe, establecer genealogías que permitan dar un sentido a la memoria y establecer la continuidad histórica de una comunidad amenazada ${ }^{22}$.

Puede que en eso resida la fuerza dramática de su prosa, que va hilando escenas fragorosas con datos precisos, el relato de los sucesos con el acecho de la locura, la 
imaginación desbocada con un aire viciado de sudor, sangre y bosta. Wald, que viene de otras ciudades, no deja de detenerse en el terrible aspecto de la Buenos Aires a oscuras, esa ciudad que, para la poesía ídish porteña del momento, era invariable e intensamente luminosa ${ }^{23} ;$ y que, en esos días trágicos, muestra su lado más tenebroso:

Cae la noche. Los negocios permanecen cerrados, con las cortinas metálicas bajas. Los tranvías no circulan. Los teatros han suspendidos sus espectáculos. Todo movimiento callejero ha muerto. La mayor parte de los faroles están rotos. La luz el éctrica está apagada. (1987, p. 331)

La indiferencia de la calle es en sí una violencia intolerable; la ciudad espectral, poderoso palimpsesto de memorias, ofrece sus propios horrores, entre ellos, el salvajismo ${ }^{24}$ de los "niños bien traídos por la tormenta":

Cerca de la puerta de un edificio está parado un chico que, seguramente, salió por un ratito de su hogar para ver el paso del "desfile"; su mirada denota curiosidad. Un "niño" le dice, de pronto, a otro:

-Un maximalistito...

El otro apunta su revólver y dispara en dirección al chico, que cae de inmediato y queda tendido inmóvil sobre la vereda.

-¡Bravo, acertaste! (1987, p. 334)

Detenido bajo la acusación de ser el presidente de la inminente república soviética en la Argentina (sic), Wald es torturado una y otra vez para que "confiese". Sin describir la tortura, su texto transmite los modos en que su cuerpo va cambiando por efecto de esta, su sensación de estar en manos de quienes lo consideran un extraño objeto, no solo merecedor de tortura, sino digno de la odiosa curiosidad de todo un torrente de visitantes:

La pesada puerta se abrió y apareció el comisario con dos altos funcionarios militares $\mathrm{y}$, además, otros dos hombres de civil, de aspecto serio. Nos observaron durante un rato y después se fueron. [...] Nuestro portón negro comenzó a abrirse y cerrarse con más frecuencia. Venían a observarnos. [...] En los oídos zumbaban toda clase de lenguas, frases y palabras; hablaban soldados, bandidos, asesinos, "niños" de cabaret, rufianes, locos, beodos: de vez en cuando irrumpía la frase:

-El presidente de la república maximalista de Argentina...

-El dictador soviético de Sudamérica...

Desde la multitud se podían oír exclamaciones: ¡El dictador! ¡El presidente!

Mi único ojo capaz de ver algo echó una mirada en derredor. Nadie sonreía... ¡Qué

chiste tremendo! [...]: Luego desfilaron frente a nosotros muchos rostros nuevos; eran los que habían estado esperando afuera para poder vernos. (1987, p. 346-48)

La multitud quería ver al "triunvirato maximalista": este es el "presidente" ... aquel es el " ministro de guerra" y el otro, el "jefe de policía" ...En ese momento, dice Wald, el mundo parecía reducirse a tres palabras: “Fuera! ¡Viva! ¡Muera!” (1987, p. 341).

En contraposición a esa curiosidad, Wald menciona otra, más "inusual”: "Crecía en mí el anhelo de conocer el grado de sufrimiento que uno es capaz de soportar; y también, hasta qué grado los seres humanos son capaces de torturar a sus semejantes" (p. 344). Es esta curiosidad la que va tensando la escena y lo lleva de a poco a una especie de delirio: “AAcaso todo eso había ocurrido en la realidad? ¿Tal vez había perdido la razón después de la primera ejecución? ¿Tal vez todo eso no era más que un delirio, fruto de una imaginación enloquecida? [...] Después, dejo errar mi mirada entre el público [...] ¿Tal vez ellos han perdido el juicio?" (p. 349).

En un momento piensa en lanzarse sobre sus torturadores, para acelerar su muerte -que creía inevitable- y terminar con todo de una buena vez, pero -dice- "precisamente en ese momento, me abrazó la añoranza por la vida. Las imágenes de mis seres queridos y 
cercanos, de mis compañeros y amigos; todos ellos aparecieron ante mis ojos. ... ¡tenía tantas ganas de echarles una mirada, antes de morir, y ver a un ser humano en plena libertad!" $(1987,351)$.

El delirio, entre el déjà vu de los pogromistas y la añoranza por los seres queridos, deviene el modo de hilvanar alguna historia que narrar para sustraerse al horror que detiene el tiempo: "¡Todo tardaba tanto en este lugar! Ni siquiera matar a alguien era algo que se hacía a tiempo" (1987, 357).

Y es precisamente el delirio lo que, cuando las palabras se deshacen, permite que irrumpa la añoranza por la vida, una añoranza que vuelve a poner en marcha el tiempo:

Esperaba la muerte y en mi mente comenzaban a confundirse imágenes de lo que iba a pasar dentro de media hora... [...] ¡Adiós, vida! ¡Adiós, mis queridos! [...] ¡Minutos, no corran con tanta rapidez! [...] Hasta ese momento, el tiempo se había detenido en un solo lugar [...] Y precisamente ahora cuando me sentía más aliviado, cuando podía respirar... de pronto, despertó en mí una enorme añoranza por la vida... Y el tiempo montó en un caballo de fuego y comenzó a galopar, con enorme rapidez (1987, p. 355).

Y, más abajo: "Cerré los ojos y, no obstante, pude ver cómo salían del agujero oscuro de la pared frente a mí, toda una banda de signos de interrogación, que iniciaron una danza diabólica a lo largo y a lo ancho de la celda" (1987, p. 362). Y entonces se suceden, una tras otra, las imágenes de la propia ejecución. Ve ante sí el fogonazo de las balas de los rifles, sin venda y contra el muro. Lo atan de pies y manos tal como se hace con un cordero (1987, p. 362) y los bomberos lo rodean con sus bayonetas dispuestas a atravesarlo. Lo conducen al patíbulo, lo suben a un banquito, le colocan el lazo en el cuello: “Delirios! ¡Fantasmas!”. Delirio es, acá, un modo de nombrar el esfuerzo por contraponer la palabra humana a un terror devastador que no cierra los ojos. Porque en el silencio mortal que rodea las visiones de Wald cuando cierra los suyos los guardianes siguen ahí, con sus ojos abiertos, como momificados (1987, p. 363).

El delirio, esfuerzo enloquecido de figurabilidad, modo desesperado de aferrarse a un hablar que se deshace es quizás la vía para abordar lo que queda desdibujado tras la discusión sobre géneros literarios: hay algo que reclama un estado de alerta que solo puede preservarse en la escritura.

\title{
La palabra en la boca
}

\author{
Perdimos una versión de nosotros mismos \\ y nos reescribimos para sobrevivir \\ Nora Strejilevich (1987, p. 150)
}

Si el texto de Wald parece rebosar de gritos y estallidos -los disparos, los cascos de los caballos contra los adoquines, "el holgorio" 25 -, el de Nora Strejilevich -Una sola muerte numerosa $a^{26}$ - parece resonar como en voz baja. No porque no haya ahí lamentos y aullidos -"Música. Descargas y música para tapar las descargas" (2006, p. 25)-, sino porque todo queda subordinado al tono indescriptible de la voz que narra: suena baja pero no es suave; habla al oído, como quien logra, trabajosamente, hacer una confidencia y, sin embargo, denuncia a voz en cuello. En esa equívoca suavidad, el hervidero de llantos y alaridos asoma a cada letra y se mezcla con palabras que, salidas de quién sabe dónde, vienen a solazarse en la dulzura de la infancia:

Un contrapunto de lamentos se arrastra desde lejos. Por la cocina, que da al templo de la calle Paso, se filtran armonías en una lengua misteriosa que acompasa 
nuestros sábados. Nunca piso la sinagoga, me basta con vivir en esta caja de música

a cuyo son descuelgo mi ropa. Música de gritos callados, acallados, calados.

-¿Qué gritabas en judío en la calle?

-Mi apellido.

-Vas a ver cómo se te acaban las ganas de tomarnos el pelo, rusita.

(Strejilevich 2006, p. 25)

El inicio de la desaparición es también el momento en que el nombre judío deja a la narradora expuesta "con una marca de diferencia, en todo caso, y no de las mejores: un interminable apellido judío, de esos trabalenguas que a los locales les exaspera pronunciar" (p. 20). De pronto, un apellido divide entre locales y... ¿qué?: ¿visitantes? ¿extranjeros? ¿ajenos? Un apellido que "parece ocupar más y más espacio con una carga de patetismo expuesto a cualquier vendaval" (p.21).

Aunque ya agobiaba desde antes, con el miedo, las corridas, con la noche en que todo estallaba y un zapateo enloquecido caía sobre el cuerpo, con el Ford Falcon sin chapas, la tortura empieza, se desata, retorna -"cuando funcionaba parecía que mil cristales se rompían, se astillaban en el interior de uno" (2006, p. 26)- y cada electrodo desgrana la versión autóctona de alguna meditación cuasi sartreana: Ser judío es, ante todo, ser visto como tal. Pero entonces -agrega el relato- no lo sabíamos (2006, p. 29) ${ }^{27}$.

La historia familiar tiene su propia clave. El secreto de la asimilación es no mirar hacia atrás. Dar media vuelta es condenarse, como la mujer de Lot, al castigo divino (2006, p. 28). Y el detentor de este secreto, el que dejó sus tradiciones en los barcos, el que solo sueña con dar a luz sangre argentina, el que quiere desprenderse por fin de ese lastre, no mira atrás. ¿Será por temor a condenarse al castigo divino? "En América no cuenta la religión. [...] una buena educación laica, con dos pilares: justicia y libertad. A Dios se lo puede olvidar, pero no que fuimos esclavos en Egipto" (2006, p. 29): Lo que para Wald era evidente, para muchos inmigrantes se volvió un silencio prolongado. Callaron la historia ante sus hijos. Entonces, ellos, los nietos, apenas entendían ya "qué es ser judío. ¿Una religión? ¿Una forma de vida? ¿Una raza? ¿Una identidad?” (Strejilevich, 2006, p. 28-29). Pero a los inquisidores tales distinciones los tienen sin cuidado. El perseguidor vive de la claridad, de las identidades definidas, aquella que el judío deshace en los intersticios de la lengua. Para ellos, lo importante era dejar claro que, si bien el más preocupante es el "problema de la subversión", el "problema judío" le sigue en importancia. Los electrodos, curiosos, reclamaban sus respuestas: nombres de personas que viajarían a Israel $^{28}$, el supuesto entrenamiento militar que recibiría en el kibutz, la descripción física de los organizadores, del edificio de la Agencia Judía, ¿algún amigo judío?, ¿un comerciante?

Luz blanca, boca seca, temblor. Bramo con tendones con músculos con sangre palabras guturales consonantes y vocales que le bajen el volumen la próxima descarga el voltaje del miedo inventar más velos quieren nombres el cerebro no responde (Strejilevich 2006, p. 29).

Y en algún lugar sin puntos ni comas, surge la historia: las palabras enlazan una genealogía de abuelas valientes en la Varsovia de 1900, la libertad perdida en un matrimonio impuesto. La llegada al Nuevo Mundo que será solo un bien de las mujeres. La poca vida de una vida poco novelesca. El abuelo, átomo del éxodo de inmigrantes a la gran ciudad. Gerardo -el hermano desaparecido-, no es sino un átomo del éxodo de inmigrantes a la clandestinidad. La historia que retorna. La vida que se aferra a leyendas hilvanadas entre fantasías y sueños.

-Si no cantás, sos boleta.

Me aseguraron que el problema de la subversión era el que más les preocupaba, pero el “ problema judío" le seguía en importancia y estaban archivando información. [...] Me 
amenazaron por haber dicho palabras judías en la calle (mi apellido) y por ser una moishe de mierda, con la que harían jabón... el interrogatorio lo centraron en cuestiones judías (p. 32).

Viejo: oigo tus pasos tenues interrumpir el mutismo del pasillo [...] $\mathrm{Tu}$ voz se resiste a modularse, sale áspera, oxidada. (2006, p. 96)

La voz que narra se desliza a la segunda persona: "Me di cuenta -dice Strejilevich en una entrevista- que estaba hablando con los muertos [...] Yo hablaba con ellos, no por ellos. Y después entendí por qué había puesto en el principio del libro 'al irse ustedes tres me dejaron con la palabra en la boca"' (2006, dedicatoria al comienzo del libro). ¿Qué hacer con esas palabras que quedaron en la boca? Palabras que son umbral de muerte y añoranza de vida. Strejilevich hace historia con ellas, hilvana una genealogía que declara perdida, una tradición que se recupera al declararla perdida en la escritura: "Aunque no sepas nada, la vas a pagar por moishe" (2006, p. 26).

Que esa puesta por escrito transite también por el delirio no sólo es un recurso, también es un modo de retomar la propia historia con esa tía que tuvo como prenda el manicomio, una penitencia por inventarse reglas que los mayores no entienden. Pero, inversamente, ahí donde no hay más reglas que el capricho impiadoso del otro, la locura es una forma de salvación, "es salirse de la lógica, anclar más atrás, donde los normales nunca llegan" (2006, p. 59).

Hay, asimismo, en el relato, un itinerario de ciudades que van reclamando palabras propias: Buenos Aires. Jerusalén. Kiriat Shmone. Florencia. España. Sitges (el otro lado de la luna $)^{29}$. Londres. Toronto. ¿Qué rumbo tomar? En cada ciudad un desencuentro la encuentra, de un lado a otro se encuentra con amores que no eran, consejos que se siguen o no; los padres, desolados los tres, en el año que empieza; la increíble ausencia de los que desaparecen por propia voluntad, como esa amiga que se fue sin dejar rastro, ni un mensaje, "ni siquiera un pedacito de papel como esos que incrustábamos en el Muro de los Lamentos para hacerle bromas a Jehová".

Invocar Su nombre, aun en vano, es un modo de buscar sentido. Sin embargo, no hay en esta frase un retorno a la fe, ni siquiera por la vía de la parodia. Se trata, en cambio, de un modo de apelar al texto -que hasta puede ser un pedacito de papel- como punto de apoyo, como ancla y manantial de fuerza. Toda la fuerza que hace falta para mantener la memoria porque la tarea es tremenda: "Nada de cerrar las heridas con ceremonias. A mí que me queden bien abiertas. La muerte y sus vueltas. No te hago monumentos, pero te llevo en el cuerpo, en las neuronas, en los pies. Te llevo a pasear, que buena falta te hace. $Y$ en el camino te cuento el desenlace de tu propia historia" (2006, p. 127).

Hay cosas que un pueblo no debe olvidar, hay cosas que un sujeto no debe olvidar. Y no se trata de confundir acá lo público y lo privado. Hablamos de sucesos de tal magnitud que atañen a todos, en palabras de Vladimir Jankélevitch (1985): una catástrofe nacional, es decir, un estado trágico, universal y radical a cuyo nivel la cosa pública se vuelve cosa privada de todos y cada uno. En este sentido, Strejilevich, en efecto, "grita en judío" cuando escribe en castellano.

\section{La palabra impronunciable}

Cuando uno cuenta los naufragios, es porque no se ahogó

Mauricio Rosencof (2010, p.145)

Las cartas que no llegaron, de Mauricio Rosencof, es la historia fragmentaria de una familia acosada por el horror, desde los campos de exterminio del nazismo hasta las mazamorras 
de la dictadura uruguaya. La historia está narrada por una única voz, -la memoria- que, alternativamente, adquiere el tono de un niño, un muchacho, un hombre. De uno a otro, navegan las palabras entre las que el silencio se vuelve aún más perceptible.

Lo judío se desliza aquí en el silencio que emana de unas cartas que no llegan, de una lengua que no se entiende, de un hombre con sombrero del Zorro que viene los domingos a matar la gallina para el puchero, de fotos en una caja, de nombres traducidos -Moishe/ Mauricio, Leibu/León/Leonel-, de una búbele que está en Polonia, que es un país de un color que no se sabe, de tíos que están en la guerra. Un silencio que se eleva de palabras recordadas a medias: guefiltefish, iberbet, latkelej, cuentenik, clapper; un silencio que conserva el eco del amor por los violines, que, en caso de pogróm, son mucho más fáciles de llevarse consigo que un piano; un silencio que estalla al gritar un nombre solo para hacer presente al nombrado (y son tantos los nombres ausentes). Un silencio que dice de abismos que interrumpen el andar de la memoria, esa memoria que hay que inventar porque las palabras quedaron atrapadas ahí. Por eso hay que escribir las cartas que no llegaron, las cartas que con su silencio dicen la historia interrumpida pero también piden formar parte de legado: "Tal vez estas cartas las escriban otros. Que Moishe sepa que también son nuestras, para que sepa qué fue de sus tíos, de sus primos, de sus abuelos. Queremos formar parte de su memoria, Isaac" (2010, p. 42).

Un silencio que no deja de hablar. Y lo hace también en las cartas, las cartas de antes, que eran otra cosa. En las cartas iba tod ${ }^{30}$. Porque esas cartas que no llegan desde la lejana Europa donde han quedado los familiares atrapados por el nazismo, parecen ser curiosamente- el anverso de una entrañable expresión ídish, por entonces muy difundida, una expresión típica de una época de migraciones: papírene kínder, hijos de papel. Así nombraban los padres a los hijos que habían emigrado y de quienes sólo podían esperar con ansias- cartas. Pero ya no hay padres que esperen las palabras de los hijos; y los hijos han perdido las palabras de los padres. Ahora son todos huérfanos de papel que añoran las palabras que nadie ya escribirá. El mismo título del libro -Las cartas que no llegaron- parece una inversión amargamente irónica -bien al modo del humor judío- de la expresión mencionada, la que aparece en la narración misma como metáfora de un hijo muerto, cuya foto mece -tan viejita ella, tan muerta (2010, p, 71)- una madre sobreviviente: “ ¿Y por qué te escribo hoy todo esto, Viejo? No sé. Tal vez para decirte lo que me acuerdo y, más que nada, decirte lo que me acuerdo, para que veas lo poco que sé, que quiero saber más, que quiero más memorias" (p. 69).

Quizás no sea casualidad que Rosencof -o quizás Moishe, el niño protagonista de la primera parte de Las cartas que no llegaron- mencione a Shólem Aleijem: su lectura enseñó a muchos que no hay contradicción entre un tono de narración íntimo y un relato histórico preciso. Quizás tampoco sea por azar el uso reiterado de la segunda persona: la memoria habla desde el fondo del silencio, a cada uno, cara a cara.

"Todos hablaban y hablaban en yiddish" ${ }^{31}$ : "Todos" quiere decir todos menos el niño que narra. La historia contada en una lengua desconocida: su resonar es un silencio que se quiere penetrar, descubrir, desentrañar. Porque el niño, que no habla esa lengua, no deja de entender la historia que se cifra en su silencio: él, que no entiende las cartas, que se aburre escuchando, dice de los tranvías que son, como los trenes, "una cosa espantosa porque se llevan a la gente y no se sabe a dónde, no los ves más” (p. 19). Por eso mismo, los uniformes son objeto de su furia salvo el del cartero, que, aunque viste uniforme, viene y va trayendo las palabras de los que están allá. Hasta que un día, no viene más. Por 
eso las cartas deberán ser escritas por otros, por alguien que no es ninguno de los personajes y no deja de ser todos.

El libro de Rosencof presenta una particularidad: al final del relato aparecen una serie de fotos -que el lector reconoce porque han sido descriptas en el relato- acompañadas cada una por un epígrafe conformado por un fragmento del texto. El lector ha sido testigo de cómo la madre enseñaba una y otra vez al niño los nombres de cada uno. "Esta es Inés, esta es... ¿quiénes son?”. Estas imágenes agregadas al final del libro han despertado más de un debate. Su presencia abona la tesis de que el libro, si bien no es estrictamente una autobiografía, no deja de ser un relato sostenido por la biografía del autor. Sofía Traballi ${ }^{32}$ sostiene, con sutileza, que estas fotos, al verse "desnaturalizadas", extrañadas de sus contextos obligados - ¿qué hace un nene en un triciclo cuando la historia que cuenta la foto es la de un exterminio?- y producen sentidos no convencionales. En esa serie resalta una foto que aparece como extraña a la narración familiar: es el portón de entrada a Auschwitz, con su infame y conocida inscripción. Trabelli otorga a la foto el valor de un cruce intempestivo entre lo privado y lo público. Recurriendo a los epígrafes y la interpolación de las fotos, el texto vuelve a poner en juego con las imágenes la complejidad de la apretada trama que conforma la historia familiar con la historia social y política que surge del relato (75).

Pero hay aún una dimensión más, creo. Algo estrechamente ligado al mundo judío de la época, a la lengua íntima de los inmigrantes: ante la inminente partida de algún miembro que cruzaría el océano en busca de tierras más propicias, la familia entera solía reunirse a fotografiarse en el cementerio, junto a la tumba de sus seres queridos. Quienes partían sabían que no habría muchas chances de volver a visitar la tumba de sus ancestros precepto valorado en el judaísmo: keiver oves- y solo podían llevar consigo la imagen de esas raíces que dejaban atrás, probablemente para siempre. ¿Pero qué es keiver oves -la tumba de los ancestros- cuando todo lo que queda es, por así decir, "papel quemado? Entiendo que la foto de Auschwitz viene a sustituir la imagen de los familiares en torno a la tumba, tan común en los emigrantes que emprendían un viaje largo e incierto. En ese sentido, las fotos no muestran sino lo que no se ve, del mismo modo que tantos dichos a medias no hacen sino recortar un silencio que sobrevuela las palabras, aunque sea en un país en estado de destierro cotidiano, ahí donde una palabra que jamás se ha oído, una palabra dicha en un idioma inexistente, retorna, impronunciable, trayendo consigo la historia: "En lo que no hay dudas, papá, es que la palabra me la dijiste vos. [...] nunca llegué a pronunciar la palabra. Pero sí su sentido, la traducción, la frase” (2010, p. 118).

\section{Las palabras en silencio}

Hemos recorrido -sin pretensiones de totalización- estos tres textos. Los tres convocan palabras como novela, crónica, autobiografía, testimonio ${ }^{33}$. Y los tres enrarecen la pregunta por el género literario, pregunta que aquí no retomaremos en términos clásicos ya que, si hubiera necesidad de establecer el género, este quizás fuera algo entre el delirio como narración desolada y desoladora, y la vigilia insomne de una memoria asediada que enlaza el presente catastrófico con una genealogía siempre amenazada. Que el delirio sea un modo de esa vigilia habla de la dimensión de irrealidad que provoca la propia experiencia cuando exige un estado de alerta permanente. Ese estado de alerta impregna la escritura judía de la catástrofe de un modo singular. Negar esa singularidad sería confundir lo 
universal -es decir, lo singular que está en todos lados- con la universalización; universalización de un lenguaje donde late la amenaza de una oscura tiranía, la de la lengua única.

En la modernidad, al perder la propia lengua ante los prestigios de la cultura occidental, los judíos perdieron de vista la hebra que enlazaba una catástrofe histórica con otra ${ }^{34}$. Pero que la hayan perdido de vista no quiere decir que no esté. Está, solo que se transmite en silencio, en lengua callada, en modos que exceden a la palabra misma. Quizás por eso el ídish de Wald está salpicado de expresiones en castellano transliteradas en letras hebreas ${ }^{35}$. Las escrituras de Strejilevitch y Rosencof -lectores borgianos de una tradición que desconocen y resguardan, transmitida por el silencio de padres que quizás quisieron preservarlos de los propios horrores-, están atravesadas, en cambio, de jirones de palabras mal recordadas, retazos de expresiones, sonidos, que se incrustan en la lengua conformando modos propios de lidiar con una historia que se porta aún si no se la conoce. Son señales vacilantes, silencios significativos, descripciones alucinadas que van hilando lo que ese nombre judío cifra en cada uno: un hombre con sombrero del Zorro, un apellido atestado de consonantes, un libro que aburre, sabores de la infancia, alguna palabra imposible de recordar o pronunciar. En el relato de ese devenir, el silencio es un modo más de la lengua: los padres que mucho no hablan, las historias que no se cuentan, las fotos enmudecidas, las cartas que no llegan.

De los tres textos, Koshmar es el único que no incluye sabores de infancia o palabras apenas recordadas de la infancia, pero Wald escribe en ídish y eso le alcanza para ubicarse. Quizás podemos decir de Wald lo que el pequeño Moishe -niño asombrado en la voz de Rosencof- dice de Sholem Aleijem: "escribía y era judío" (Rosencof, 2010, p. 53).

Ese silencio que estos textos perciben y transmiten semeja esas llaves oxidadas que los judíos de Salónica conservaron y pasaron de padres a hijos después de la expulsión en el siglo XV, como las llaves que tantos llevaron a Auschwitz pensando en volver a utilizarlas. El silencio de esos objetos en apariencia inútiles, conservados por generaciones -metáfora inquietante de una transmisión sin palabras-, circula entre los autores aquí convocados. Ellos, a sabiendas o no, retoman con potencia literaria lo que ese silencio les ha transmitido: una de las tradiciones judías más vitales, que es la de la respuesta judía textual a los sucesos catastróficos. En estas escrituras, en las que se percibe un fuerte impulso de recapitulación, la tradición resurge transformada en términos secularizados, como flashbacks históricos, como leyendas, como genealogía. Este sentido de recapitulación es una constante en la historia judía, lo que se traduce no sólo en el empecinamiento por preservar la memoria de lo ocurrido, sino por la persistencia del recurso a la escritura como arma. A sabiendas o no, estos autores han hecho lo que tantos antes de ellos: asomarse al abismo que señala el término judío y luego retirarse, alucinados, en busca de palabras. 


\section{BIBLIOGRAFÍA}

Botoshansky Iankev, "La primera generación de escritores ídish en la Argentina”, en Crónicas judeoargentinas/1 - Los pioneros en ídish 1890-1944, Colección Imaginaria; Dir. R. Feierstein; Milá Bs. As. 1987 , p. 11-23

Di Mario María Cecilia, "De crónicas y escrituras en la Semana Trágica”, Cuaderno de trabajo ㄲo 83 1a ed. - Buenos Aires, Centro Cultural de la Cooperación Floreal Gorini, 2008

Dimentstein Marcelo David (UNGS /CONICET). “En busca de un pogrom perdido: diáspora judía, política y políticas de la memoria en torno a la SemanaTrágica de 1919 (1919-1999), www.sociohistorica.fahce.unlp.edu.ar/

Dobry Edgardo, "Pizarnik y Gelman ante la ley inaccesible", en Cuadernos LIRICO - Revista de la red interuniversitaria de estudios sobre las literaturas rioplatenses contemporáneas en Francia, no 17, año 2017: https://journals.openedition.org/lirico/3914

Feierstein Ricardo, Historia de los judíos argentinos, Ed. Galerna, Bs.As., 1993

Ferrer Christian, “Una semana de enero de 1919”, Buenos Aires ídish - Temas de Patrimonio Cultural Vol. 19 (Compilación, edición y notas: Perla Sneh), CPPHC, Gobierno de la CABA, 2006; p. 93-99 Jankéleitch Vladimir, Lo imprescriptible / ¿Perdonar? Con honor y dignidad, Muchnik Editores, 1985 Kairuz Mariano "Los abuelos del Falcon verde" (sobre "Un pogrom en Buenos Aires", de Szwarcbart, Hernán); Pagina/12, Suplemento Radar, 2 de diciembre, 2007

Kaufman Alejandro, "Idishkayt- Memorias sobre poder y violencia", en Buenos Aires Ídish Temas de patrimonio cultural. Vol. 19, CPPHC de la CABA, Bs. As., 2006, p. 31-35

Korin Moishe, “A noventa años de la Semana Trágica: Pinie Wald, una víctima”, Mundo Israelita, viernes, 13 de febrero de 2009, consultado el 20 de abril en http://www.mundoisraelita.com.ar/ index.php?option=com_content\&task=view\&id=1316

Rosencof Mauricio, Las cartas que no llegaron, Alfaguara, 2010

Roskies David, Against the Apocalypse: Responses to Catastrophe in Modern Jewish Culture, 1984

Schiller Herman, “El primer 'pogrom”, Página/12, Bs.As. 3 de enero, 1999

Sneh Perla, "La ciudad de los poetas", en Buenos Aires ídish - Temas de Patrimonio Cultural Vol. 19 (Compilación, edición y notas: Perla Sneh), CPPHC, Gobierno de la CABA, 2006, p. 71-76

--, Palabras para decirlo - Lenguaje y exterminio, Ed. Paradiso, Bs.As., 2012

Strejilevich Nora, Una sola muerte numerosa, Ed. Alción, Córdoba, 2006

Traballi Sofía, "Narrar desde las fronteras: Memoria y experiencia de la violencia en Las cartas que no llegaron de Mauricio Rosencof", en Anclajes vol. XVIII no 2 (diciembre 2014) p. 61-78; p. 62 n.1

Wald Pinie, "Pesadilla”, en Crónica judeoargentinas -Los pioneros del ídish 1890-1944, Colección Imaginaria dirigida por R. Feierstein, Trad.: S. Sneh, AMIA/ Milá, Bs. As., 1987, p. 327-407

Zambrano Andrea, "Entrevista a Nora Strejilevich", Revista Transas, Letras y artes de América Latina, UNSAM, http://www.revistatransas.com/2016/08/25/nora-strejilevich-el-testimonio-no-es-unacopia-de-la-realidad-sino-su-construccion 
Zipperstein Steven J., Pogrom: Kishinev and the Tilt of History, Liveright, 2018. Para una lista de víctimas, véase https://kehilalinks.jewishgen.org/chisinau/LIF_POGROM1903_Victims.asp

\section{NOTAS}

1. Si bien los tres están asociados a movimientos de izquierda, la experiencia ideológica y existencial fue diferente para cada uno. Wald fue miembro comprometido del Bund y uno de los fundadores en Buenos Aires de Avangard, organización que aspiraba a integrarse al Partido Socialista argentino; al mismo tiempo, no dejó de participar de la vida comunitaria, especialmente en el área de educación, en la que fue un destacado activista. Mauricio Rosencof tuvo una militancia muy comprometida en tanto miembro fundador del Movimiento de Liberación Nacional "Tupamaros", por lo que estuvo doce años encarcelado por la dictadura militar en Uruguay (1973-1983) en terribles condiciones. Por su parte, Strejilevich tuvo una militancia más tímida "sin la convicción de la victoria, pero con el deseo". (Strejilevich, Nora Una sola muerte numerosa, Ed. Alción, Córdoba, 2006, p. 52). Como ella misma dice: Tardo varios años en planificar mi huida, demasiados. Antes que caiga la cortina final, me bajo del escenario en puntas de pie [... ] Nadie lo notará, no soy tan importante. Me equivoqué. Alguien lo notó (USMN, p. 53).

2. Pinie Wald (Tomaschov, Polonia, 15 de Julio, 1886 - Bs. As. 25 de agosto, 1966). Su destino de proletario judío lo trajo a la Argentina, a raíz del primer estallido revolucionario de 1905 en la Rusia zarista. Por su militancia en el "Bund", debió desarraigarse del viejo hogar cuando la revolución fracasó y así llegó a Argentina, donde perseveró en sus ideales hasta el fin de sus días. Formó un hogar con Rosa Wainstein (fallecida en 1978); tuvieron dos hijas: Eva y Flora Margarita; y cuatro nietos. Además de Koshmar, publicó una obra extensa e interesante: Blétlej (1929), monografía colectiva de dieciséis personalidades de la incipiente comunidad; e In gang fun tzaytn ("Al paso de los tiempos") (1959), una historia del socialismo en la Argentina; del mismo año es "Oif histórische vegn" ("Por caminos de la historia"), de casi 400 páginas, con monografías sobre Mariano Moreno, Manuel Belgrano, Esteban Echeverría, Nicolás Repetto, Miguel Pólak, Mordje Alpersohn y Enrique Dickmann; también sobre Sarmiento, Alberdi, Urquiza y Juan B. Justo. En 1964, se publicó Gueshtaltn fun ídischn velt-folk ("Figuras del pueblo judío universal"), con monografías sobre Vladimir Médem, Hirsch Lékert, Itzjok Blind, Ruye y Sigmund Gyivach, entre otros. Arguentine ("Argentina”), también de 1966, sería su adiós al mundo. Cfr. Korin, Moishe, “A noventa años de la Semana Trágica: Pinie Wald, una víctima", Mundo Israelita, viernes, 13 de febrero de 2009, consultado el 20 de abril de 2018 en http://www.mundoisraelita.com.ar/ index.php?option=com_content\&task=view\&id=1316

3. Nora Strejilevich (1951) es una escritora y docente argentina que ha centrado su trabajo de escritura e investigación en el legado del genocidio a partir de su experiencia personal: en 1977 fue secuestrada y permaneció varios días desaparecida en un centro clandestino de detención llamado "Club atlético". En el mismo lugar estaban secuestrados su hermano Gerardo, la novia de éste -Graciela Barroca- y su primo Abel y al hermano de éste, Hugo. Todos permanecen desaparecidos hasta hoy. Nora fue liberada y partió rumbo a un exilio múltiple (Israel, España, Italia, Brasil, Inglaterra y Canadá) hasta que se afianzó en San Diego (USA). Ha publicado, entre otros, Inventario, Anamnesis, Too Many Names. También es autora de El arte de no olvidar: literatura testimonial en Chile, Argentina y Uruguay entre los' 80 y los' 90 (2006), y tiene dos libros en prensa: El lugar del testigo. Escritura y memoria, y Un día, allá por el fin del mundo. Una sola muerte numerosa, texto que aquí nos ocupa, ha sido reeditado en España en 2018 por la editorial Sitara.

4. Mauricio Rosencof (Florida, Uruguay, 30 de junio de 1933) es dramaturgo, poeta, narrador y periodista. Fue fundador de la Unión de Juventudes Comunistas y dirigente del Movimiento de Liberación Nacional - Tupamaros (MLN-T). Fue detenido y torturado y, tras el golpe de Estado de 1973, fue declarado "rehén" junto a ocho reclusos más, lo que significaba la muerte inmediata si 
algún acto exterior amenazaba la seguridad de las Fuerzas Armadas. Tras doce años de cárcel, fue liberado en 1985 al ser promulgada una ley de amnistía para los tupamaros. Nombramos aquí algunos títulos de su profusa obra: El gran Tuleque (1960), Las ranas (1961), Los caballos (1967), El combate del establo (1985), El regreso del Gran Tuleque (1987), El hijo que espera (1988), Memorias del calabozo (en coautoría con Eleuterio Fernández Huidobro, 1989, reimpreso en 2013 con prólogo de Eduardo Galeano), La margarita. Historia de amor en 25 sonetos (1994, obra que fue musicalizada por Jaime Roos), Leyendas del abuelo de la tarde (2004), Una góndola ancló en la esquina (2007), Medio mundo (2009), Lo grande que es ser chiquito, (2010), Il Duce (libreto de ópera con música de Federico García Vigil e/c con Carlos Maggi, 2013).

5. En tanto profesora e investigadora, Nora Strejilevich también escribe en inglés e incluso ha colaborado en la traducción de su propia obra a ese idioma, pero reiteramos que nos limitamos a este escrito específico.

6. Seguimos aquí las elaboraciones de David Roskies, en Against Apochalypse - Responses to Catastrophes in Modern Jewish Culture, Syracuse University Press, 1999.

7. Koshmar apareció en ídish en 1929. El texto permaneció ajeno a la lengua argentina hasta 1987, cuando fue traducido al castellano por el escritor Simja Sneh y publicado como Pesadilla en Crónicas judeoargentinas -. Los pioneros en ídish. 1890-1944, Colección Imaginaria (Dir. R. Feierstein), pp.327-407. En 1998, el escritor Pedro Orgambide volvió a publicarlo en la editorial Ameghino bajo el título Pesadilla. Una novela de la Semana Trágica.

8. Strejilevich Nora, Una sola muerte numerosa, Ed. Alción, Córdoba, 2006. La primera edición es de 1996.

9. Rosencof Mauricio, Las cartas que no llegaron, Alfaguara. Bs. As., 2010. La primera edición data de 2000.

10. No fue el primero; en 1909 Simón Radowitsky atentó contra la vida del jefe de la policía Ramón L. Falcón, artífice de la represión contra los obreros el 1ํ de Mayo de ese año. Después del atentado hubo represalias, agresiones y ataques a instituciones judías; por ejemplo, la sede del Avangard (el órgano de prensa del Bund), y la Biblioteca Rusa (con quema pública de sus libros en la plaza Congreso). Cfr. Feierstein Ricardo, Historia de los judíos argentinos, Ed. Galerna, Bs.As., 1993 11. No se ha podido establecer el número exacto de muertos: oscilan entre setecientos y mil trescientos, según las distintas fuentes. Quizás dos o tres mil heridos. Detenidos: unos treinta mil, cifra inquietante para cualquier oído argentino. Cfr. Ferrer, op. cit.

12. La actividad fue calificada por La Nación como "errada pero bienintencionada". Cfr. Di Mario, María Cecilia, De crónicas y escrituras en la Semana Trágica, Cuaderno de trabajo no 83 - 1a ed., Buenos Aires, Centro Cultural de la Cooperación Floreal Gorini, 2008. Para Herman Schiller, la denominación de "rusos" (en lugar de judíos) data de los sucesos de 1919 y se hizo aún más frecuente cuando la colonia de Moisés Ville (Santa Fe) saludó públicamente el triunfo de la revolución encabezada por Lenín. Asimismo, cuenta Schiller sobre el pogróm: “José Mendelsohn, un joven periodista que venía de las colonias agrarias del Interior (y a quien conocí en la década del cincuenta cuando este escritor y pedagogo ejercía la dirección del Seminario para Maestros Hebreos que funcionaba en el segundo piso de la AMIA, Pasteur 633), testimonió en Di Idische Tzaitung del 10 de enero el salvajismo de esos días: "Pamplinas son todos los pogromos europeos al lado de lo que hicieron con ancianos judíos las bandas civiles en la calle, en las comisarías $7^{a}$ y 9ª , y en el Departamento de Policía. Jinetes arrastraban a viejos judíos desnudos por las calles de Buenos Aires, les tiraban de las barbas, de sus grises y encanecidas barbas, y cuando ya no podían correr al ritmo de los caballos, su piel se desgarraba raspando contra los adoquines, mientras los sables y los látigos de los hombres de a caballo caían y golpeaban intermitentemente sobre sus cuerpos"; Cfr. Schiller, Herman, "El primer pogróm”, Página/12, Buenos Aires, 3 de enero de 1999. 13. Koshmar (idish: Pesadilla), Bs. As., 1929. No figura editorial. El texto puede consultarse en la Biblioteca Digital del Yiddish Book Center, Amherst, Massachusetts. www.yiddishbookcenter.org 
14. Di Mario María Cecilia De crónicas y escrituras en la Semana Trágica, cuaderno de trabajo № 83 1a ed. - BS. As., Centro Cultural de la Coop. Floreal Gorini, 2008

15. Di Mario, op. cit.

16. Kairuz Mariano, "Los abuelos del Falcon verde"- Sobre "Un pogróm en Buenos Aires", de Hernán Szwarcbart, en Pagina/12, Suplemento Radar, 2 de diciembre, 2007.

17. Idem.

18. En la "Nota Preliminar" de su edición de Pesadilla, Orgambide asegura que esta novela "parece anticipar la técnica de la real-fiction (Truman Capote) y, entre nosotros, los memorables trabajos de Rodolfo Walsh". Agrega que la "alternancia entre la novela y la crónica, entre lo folletinesco y lo periodístico [...], es, seguramente, uno de los atractivos de este libro". Citado por Di Mario, op. cit.

19. Jaim Najman Bialik, el poeta que revolucionó la historia de las respuestas judías a la destrucción después del pogróm de Kishinev -precisamente, el que eyectó de Europa a Wald- con su poema "En la ciudad de la matanza" (Be’irHa'arigá).

20. El presidente es el que ha lanzado la primera bomba y bebió la sangre del soldado, cuyo cuerpo se hizo pedazos; ésta es su manera de proceder... (p. 348)

21. Los terribles pogromos de Kíshinev, que tuvieron lugar el 19 y 20 de abril de 1903, conmocionaron a los judíos de Rusia. Sus protagonistas asesinaron con saña a cuarenta y nueve judíos, entre ellos niños pequeños; hirieron, violaron, depredaron. Y todo con la total anuencia y el beneplácito de las autoridades. Véase al respecto: Steven J. Zipperstein, Pogrom: Kishinev and the Tilt of History, Liveright, 2018. Para una lista de víctimas, véase https://kehilalinks.jewishgen.org/ chisinau/LIF_POGROM1903_Victims.asp

22. David Roskies, op. cit.

23. Luminosidad epitomizada en el entrañable verso de José Rabinovich, en traducción de Eliahu Toker: Una ciudad tan luminosa y yo andando a tientas... Cfr. Sneh, P., "La ciudad de los poetas", en Buenos Aires ídish - Temas de Patrimonio Cultural (Compilación, edición y notas Perla Sneh), Vol. 19, CPPHC, Gobierno de la CABA, 2006 pp. 71-76.

24. Más tarde, Wald leerá a -y escribirá sobre- Sarmiento; ahí se encontrará con la dicotomía argentina "civilización o barbarie". Por entonces, solo dispone del "salvajismo" europeo.

25. Arturo Cancela, a los pocos meses de los hechos, escribió el primer un relato sobre la Semana Trágica bajo el título de "Una semana de holgorio" incluido en Tres relatos porteños, publicado en España en 1923.

26. Strejilevich, Nora, Una sola muerte numerosa, Alción Editora, Córdoba, 2006. Esta obra dio a su autora reconocimiento internacional y ha sido traducido al inglés y al alemán. Actualmente, está siendo traducida al italiano. (La edición de 1997 es de Miami: University of Miami, 1997. En 1996 el libro fue premiado en USA, en el concurso de literatura hispánica Letras de Oro, y de allí que fuera traducido y publicado al año siguiente).

27. "El objetivo durante la dictadura fue acabar primero con los llamados subversivos, o sea con los Montoneros y otras organizaciones revolucionarias, y en segundo lugar con los judíos. Al menos eso es lo que me dijeron cuando me interrogaron por judía. En relación al vínculo con lo que fue el genocidio más paradigmático del siglo pasado [la Shoah], yo diría que el nuestro es una reencarnación simbólica. Se pueden por supuesto enfatizar las diferencias, que son muchas, pero el Mal con mayúsculas va asumiendo formas emparentadas. Quiero decir que hay un mismo ADN en la genealogía del Mal." Entrevista a Nora Strejilevich de Andrea Zambrano. Revista Transas, Letras $y$ artes de América Latina, UNSAM http://www.revistatransas.com/2016/08/25/norastrejilevich-el-testimonio-no-es-una-copia-de-la-realidad-sino-su-construccion/

28. Nora Strejilevich fue detenida en inminencia de su viaje a Israel como parte del programa "Sherut La'am".

29. "Viniendo de Israel, España es el otro lado de la luna", cfr. Strejilevich, 2006, p. 111.

30. "En una carta iba todo", Rosencof, 2010, p. 73. 
31. La grafía "Yiddish" -en vez de "ídish"- que figura en el texto de Rosencof amerita recordar las palabras de Alejandro Kaufman: El exterminio no solo produjo la ausencia de millones de almas, sino de sus formas de hablar y de vivir, que nos demandan hospitalidad, más que memoria, en nuestra época y en nuestras biografías. Y agrega, en una nota al pie: Hospitalidad sobre la que cabe interrogarnos -desde un punto de vista institucional-respecto de la lengua castellana, cuyo diccionario de autoridad, el de la RAE, no comprende la voz "ídish", en cambio destinada al Diccionario hispánico de dudas con la siguiente definición y curiosa transliteración: "yidis. Adaptación gráfica propuesta para la voz inglesa yiddish-adaptada, a su vez, del adjetivo alemán jüdisch ('judío') -, que designa el dialecto alto alemán hablado por los judíos originarios de la Europa central y oriental, que se escribe en caracteres hebreos: «El yidis es el idioma que hablaron los judíos (Moreno Lenguas (Esp. 1990)". [...] Interrogarnos sobre las causas, no sobre la evidencia de la hostilidad que manifiestan estas definiciones: dan por muerto al ídish ( "hablaron") y hacen provenir la palabra del inglés o del alemán, pero ¡no del ídish! Cfr. Kaufman, Alejandro, "Idishkayt- Memorias sobre poder y violencia", en Buenos Aires Ídish - Temas de patrimonio cultural. Vol. 19, CPPHC de la CABA, Bs. As., 2006, p. 31-35.

32. Traballi, op. cit

33. Suele considerársela "novela" (de hecho el término está en el título de algunas ediciones), pero también "crónica", testimonio", etc. Ver Di Mario, M. Cecilia, De crónicas y escrituras en la Semana Trágica, Cuaderno de Trabajo n⿳o 83, Centro Cultural de la Cooperación Floreal Gorini, Bs.As. 2008. En cuanto a Las cartas que no llegaron, Sofía Traballi la considera "novela autobiográfica". Ver "Narrar desde las fronteras: Memoria y experiencia de la violencia en Las cartas que no llegaron de Mauricio Rosencof”, en Anclajes vol. XVIII no 2 (diciembre 2014) ISSN 1851-4669, pp. 61-78. P. 62 n.1

34. Roskies, op. cit.

35. "Bomberos", “Tierra del Fuego", "Orden social”, así como los nombres de muchas calles, el apelativo de diversos personajes y sus títulos oficiales, aparecen transliterados en letras hebreas provocando un extraño efecto en el lector ídish hispano parlante.

\section{RESÚMENES}

Este trabajo aborda la obra de tres autores rioplatenses, pertenecientes a generaciones distintas, que abarcan todo el arco del siglo XX: Pinie Wald, Mauricio Rosencof y Nora Strejilevich. Cada uno de ellos vivió, y reflejó en sus obras, distintas experiencias traumáticas de la vida política argentina y europea: la violencia antisemita durante los sucesos de la "semana trágica" (enero de 1919) en Wald, que escribió en ídish; el exterminio nazi, bajo la forma de "cartas que nunca llegaron", en Rosencof; y el terrorismo de Estado durante la última dictadura, en Strejilevich. Aunque ninguna de estas obras limita su foco a las cuestiones vinculadas con el judaísmo, este es un elemento central en todas ellas, y es el que sirve de hilo para la serie que este artículo elabora y analiza.

Cet article étudie les oeuvres de trois auteurs du Rio de la Plata qui, appartenant à différentes générations, illustrent le XX e siècle: Pinie Wald, Mauricio Rosencof et Nora Strejilevich. Leurs oeuvres respectives reflètent à leur manière des expériences traumatiques diverses ayant émaillé la vie politique argentine et européenne de ce siècle: l'antisémitisme pendant la "semaine 
tragique" (janvier 1919) chez Wald, dont sa langue d'écriture était le yiddish; l'extermination nazi, sous la forme de "lettres qui ne sont jamais arrivées", chez Rosencof; et le terrorisme d'État pendant la dernière dictature argentine, chez Strejilevich. Même si aucune de ces oeuvres ne restreint son champ à la thématique juive, le judaïsme en est le centre, fil conducteur des idées que cet article développe.

This article puts under study the works of three authors from Rio de la Plata, each belonging to a different generation and illustrating the $20^{\text {th }}$ century: Pinie Wald, Mauricio Rosencof and Nora Strejilevich. Through their works they each give a personal account on traumatic experiences that took place in that century in both European and Argentinian political lives : the antisemitism during the "Tragic Week" of January 1919 in Wald's, of whom the writing language was Yiddish; the Nazi genocide told through the means of "letters that were never delivered" in Rosencof's; and the State terrorism of the last Argentinian dictatorship in Strejilevich's. Even if none of these works narrow down their study domain to the Jewish topic, Judaism is both a key notion and the red thread in the ideas this article expands on.

\section{ÍNDICE}

Mots-clés: Pinie Wald, Nora Strejilevich, Mauricio Rosencof, Semaine Tragique, disparition et exile, témoin et écriture, transmission.

Palabras claves: Pinie Wald, Nora Strejilevich, Mauricio Rosencof, Semana Trágica, desaparición y exilio, testimonio y escritura, transmisión.

Keywords: Pinie Wald, Nora Strejilevich, Mauricio Rosencof, Tragic Week, disappearance and exile, testimony and writing, transmission.

\section{AUTOR}

\section{PERLA SNEH}

Universidad Nacional de Tres de Febrero 